\title{
POVOS E TERRITÓRIOS TRADICIONAIS NO BRASIL SOB A PERSPECTIVA DOS DIREITOS DA SOCIOBIODIVERISDADE
}

\section{TRADITIONAL PEOPLE AND TERRITORIES IN BRAZIL FROM THE PERSPECTIVE OF THE RIGHTS OF THE SOCIOBIODIVERSITY}

\author{
1Matheus Silva de Gregori \\ ${ }^{2}$ Luiz Ernani Bonesso de Araujo
}

\section{RESUMO}

O presente trabalho investiga a problemática territorial que envolve os povos tradicionais no Brasil, abordando fundamentos dos direitos étnicos e culturais da sociobiodiversidade, no sentido de garantir o espaço de reprodução social dessas comunidades. O método de abordagem é a realizado desde uma perspectiva sistêmico-complexa. Conceitua-se "povos tradicionais", desde concepções antropológicas, sociológicas e jurídicas, considerando as territorialidades e particularidades da formação do espaço territorial brasileiro, e contrastando-as, após, com a realidade da globalização econômica e a forma política e jurídica da propriedade moderna. Afirma-se a importância da promoção dos direitos étnicos e culturais que assistem os povos tradicionais.

Palavras-chave: Direito, Povos tradicionais, Sociobiodiversidade, Território

\begin{abstract}
This work investigates the territorial issue involving traditional peoples in Brazil, addressing grounds of ethnic and cultural rights of sociobiodiversity, to ensure the social reproduction of these communities in space. The approach method is done from one systemic and complex perspective. Conceptualizes up "traditional peoples" from anthropological, sociological and legal conceptions, considering territoriality and peculiarities of formation of the Brazilian territorial space, and contrasting them later with the reality of economic globalization and the political and legal form of the modern property. It is stated the importance of the promotion of ethnic and cultural rights of the traditional peoples.
\end{abstract}

Keywords: Law, Traditional people, Sociobiodiversity, Territory

\footnotetext{
1 Mestrando em Direito pelo Programa de Pós-Graduação em Direito da Universidade Federal de Santa Maria. Advogado. Universidade Federal de Santa Maria - PPGD-UFSM, Santa Maria. Brasil

E-mail: matheusdegre@gmail.com

2 Doutorado em Direito pela Universidade Federal de Santa Catarina. Professor da Universidade Federal de Santa Maria. Universidade Federal de Santa Maria - PPGD-UFSM, Santa Maria. Brasil

E-mail: luiz.bonesso@gmail.com
} 


\section{INTRODUÇÃO}

O Brasil, intensamente exuberante em riqueza biológica e sociocultural biodiversidade e diversidade humana - aparece como um palco saturado de conflitos de interesses, tensões entre a natureza e o homem e entre grupos sociais distintos, na construção histórica da ocupação do território. Nesse contexto, destaca-se uma temática específica que vem sendo debatida contemporaneamente: os povos e comunidades tradicionais. Com efeito, a globalização, sobretudo no seu aspecto econômico, incita e intensifica as contradições (e opressões), inauguradas na internacionalização colonizadora européia no século $\mathrm{XV}$, resultantes do entrechoque de culturas, cosmovisões e modos de produção. As sociabilidades e modelos de reprodução econômica e social dos povos locais e tradicionais - em geral ecologicamente sustentáveis - aparecem como resistência contra-hegemônica à mercantilização do mundo e da vida, suscitando sua defesa e autonomia como questão de destaque em meio à matéria da proteção do meio ambiente latu sensu.

Juridicamente falando, é possível extrair de alguns documentos internacionais e normativos internos (destacando-se, inclusive, a Constituição Federal) a referência aos povos tradicionais. São definições, conceitos, políticas de promoção e o aqui especialmente tratado: a afirmação territorial dos povos $\mathrm{e}(\mathrm{m})$ suas específicas territorialidades. A esses pontos buscou-se agregar contribuições de outras áreas do saber (antropologia, sociologia, economia e ecologia política, etc), procurando-se uma visão que escapasse de um enclausuramento juridicista, em vista da inerente transdisciplinariedade do Direito Ambiental. A isso se soma a necessidade de uma abertura epistemológica da ciência jurídica - dogmática e cartesiano- linear - como requisito para lidar adequadamente com a temática proposta.

A abordagem utilizada para enfrentamento da temática é a perspectiva sistêmicocomplexa. A humanidade, neste sentido, é vista como a tríade indivíduo-sociedade-espécie, com a necessidade de "religação" de tais instâncias, com a inclusão da mediação sistema- meio. Parte-se de princípios propostos por Edgar Morin (2011), (dialógico, da recursão organizacio nal, etc) que pretendem a superação da visão cartesiana, visto que é impossível tanto isolar um sistema (pensamento simplificador) como olhar o todo de forma holística ("a totalidade é a nãoverdade"). O meio Ambiente, assim, não é visto como sinônimo apenas de natureza, mas da própria imbricação entre o humano (tríade indivíduo-sociedade-espécie) e o ambiente, sendo que a política e o direito (como linguagem e poder simbólico) aparecem como mediadores dessa relação. $\mathrm{Na}$ abordagem sistêmica, por sua vez, as propriedades das partes podem ser 
entendidas apenas a partir da organização do todo, pois apresentam características que, na análise isolada, não se manifestam.

Neste sentido, tal perspectiva é adequada para o tratamento do tema proposto, na medida em que são consideradas as comunicações possíveis entre os saberes das ciências naturais e das sociais, procurando articular os processos, relações, causalidades e interdependências que se estabelecem entre os sistemas. Com efeito, o pensamento sistêmico "concentra-se não em blocos de construção básicos, mas em princípios de organização básicos. O pensamento sistêmico é 'contextual', o que é o oposto do pensamento analítico." (CAPRA, 2001).

Em vista disso, é brevemente abordado o papel do Direito e do Estado, especificame nte na via jurisdicional, no balizamento jurídico das promessas (políticas) constitucionais. Isso se deve porquando, ao se identificar um "estatuto jurídico" dos povos tradicionais, cabe a defesa de uma atuação jurídica que preze uma interpretação do direito que, no sopesamento de interesses, efetive os direitos fundamentais e constitucionais, mesmo que em choque com outros mais "clássicos" que devem ser relativizados (v.g. propriedade), em uma perspectiva de "sociobiodiversidade".

Sugere-se que a politização do conhecimento é imprescindível para a reapropriação social da natureza, ou seja: para que o meio sirva aos interesses humanos, e não somente à lógica do capital. Isso posto, evidencia-se a relevância acadêmica da pesquisa realizada. Com efeito, os conflitos ambientais que envolvem povos tradicionais devem ser amplamente tratados e discutidos no âmbito da academia, especialmente na área do direito - e principalmente no que toca a afirmação de territórios tradicionais - na medida em que a decisão jurídica, e os pressupostos de sua interpretação, podem e devem oxigenar-se com princípios de pluralismo jurídico e interculturalidade, aqui prolatados como ótica fundamental.

\section{POVOS TRADICIONAIS: APORTES JURÍDICOS E CONCEITUAIS}

Sabe-se que, como resultado da interação de diferentes grupos humanos com múltiplos ecossistemas planeta, apresentam-se as mais variadas formas de exploração e apropriação do território natural. Com efeito, a variedade biológica congrega-se, historicamente, a partir diferentes processos de relação com o humano, com a diversidade cultural, compreendida como as distintas formas de uso, apropriação e exploração do território. 
Parece legítimo dizer, quando se pondera sobre a questão fundiária e ambiental, que essa perpassa necessariamente pelo exame da cultura, na medida em que é a maneira como se significa o mundo e as coisas - os aspectos culturais - que determina as bases em que o homem se assenta para se relacionar com a natureza, e que se refletem nas dinâmicas sociais, econômicas e políticas de cada comunidade. Em outros termos: as variadas cosmovisões humanas refletem a diversidade de relacionamento entre as sociedades e o meio ambiente.

Neste sentido, pode-se dizer que os vínculos entre natureza e cultura remontam aos princípios do desenvolvimento linguístico-simbólico do homem, no momento em que este amplia suas capacidades de imaginação e abstração, talvez até antes de qualquer coisa que se convencione a chamar de "civilização". Por óbvio que, em todo conjunto de indivíduos, os usos que se faz do ambiente e dos recursos naturais não se limitam às necessidades práticas (alimentação, atributos medicinais, etc.), mas se estendem também às significações místicas, simbólicas e identitárias que mantém vivo o senso de pertencimento ao grupo e de solidariedade social.

A diversidade socioambiental, em outros termos, as variadas formas de uso e ocupação do território, bem como as culturas e conhecimentos e associados à biodiversidade oriundos dessa variabilidade, podem ser considerados em termos de sociobiodiversidade ${ }^{l}$, como será mais bem explicado adiante.

O território brasileiro, dotado de extensões "continentais", compreende uma quantidade extraordinária de ecosssitemas, sendo formado por seis biomas de características distintas: Amazônia, Caatinga, Cerrado, Mata Atlântica, Pantanal e Pampa. À vista disso, e por estar quase em sua totalidade em faixa do globo entre trópicos (tropical), o país conta com uma variedade vegetal e animal definitivamente abundante, sendo o mais rico em biodiversidade entre aqueles países considerados megadiversos $^{2}$. Dessa diversidade biológica origina-se uma diversidade de culturas.

\footnotetext{
1 Existe um vínculo histórico entre diversidade sociocultural e biodiversidade. Na antropologia, trabalhos recentes de etnocientistas e arqueólogos mostram como a existência de biodiversidade pode ter resultado das distintas formas de apropriação e proteção da nat ureza por parte de diferentes grupos sociais - isto é, a sociodiversidade - em processos de "co-evolução" (Neves, 1992 apud Little, 2002). Como também refere Viveiros de Castro (2008, p. 102): “A 'mata virgem' tem muito de fantasia: como hoje se com eça a descobrir, boa parte da cobertura vegetal amazônica é o resultado de milênios de intervenção humana: a maioria das plantas úteis da região proliferou diferencialmente em função das técnicas indígenas de aproveitamento do território e porções importantes do solo amazônico (no mínimo $12 \%$ da superfície total) são antropogênicas, o que indica uma ocupação intensa e antiga. Em síntese, a floresta que os europeus encontraram quando invadiram o continente era o resultado da presença de seres humanos, não de sua ausência."

2 Os países megadiversos são 17 países, entre as duzentas nações do mundo, que possuem em seus territórios cerca de $70 \%$ da biodiversidade de todo o planeta. Esta conclusão foi fruto de estudo apresentado em Washington/EUA pela organização ambiental Conservation International. Gráficos em http://www.environment.gov.au/node/21579 (Acesso em http://www.biodiversitya- z.org/areas/26(Acesso em 07jun2015).
} 
Especificamente, além das inúmeras populações humanas (indígenas) que povoavam a extensão que hoje compreende o Brasil, foram agregados, durante o processo histórico da colonização ibérica, diversos outros grupos de indíviduos, dentre os quais os escravos africanos. Além destes, por meio da miscigenação ${ }^{3}$, diversos outros grupos minoritários - em termos de poder político-econômico - construíram suas dinâmicas próprias de sociabilidade, sendo que, em sua maioria, criaram vínculos com o meio ambiente pelos quais mantiveram seu meio de vida e subsistência.

Esses diversos grupos que formam a sociobiodiversidade brasileira podem ser considerados como "povos" ou "comunidades" tradicionais, sendo que sua definição será abordada mais profundamente a seguir. Por esses grupos representarem formas contrahegemônicas de reprodução social, são suscitados conflitos jurídicos em torno de seus direitos. De fato, a questão fundiária brasileira ultrapassa a demanda da redistribuição, ressaltando-se aqui o aspecto da afirmação territorial, compreendida como a necessidade de manutenção e resguardo das comunidades nos meios que necessitam para sua reprodução social e cultural.

\subsection{Territorialidade e formação territorial do Brasil}

A territorialidade, sob um viés antropológico, é um aspecto que considera a forma de relação das sociedades com o seu território, sendo que este é um elemento de conduta presente em todo e qualquer agrupamento humano. Little (2002, p. 2), define territorialidade como o "esforço coletivo de um grupo social para ocupar, usar, controlar e se identificar com uma parcela específica de seu ambiente biofísico, convertendo-a assim em seu território ou homeland". Para compreender o vínculo específico que cada sociedade sustenta com seu território, o mesmo autor utiliza o conceito de cosmografia ${ }^{4}$, definida (LITTLE, 2002, p.4) como "os saberes ambientais, ideologias e identidades - coletivamente criados e historicamente situados - que um grupo social utiliza para estabelecer e manter seu

\footnotetext{
3 Alguns teóricos, como Gilberto Freyre, chegaram a assegurar que tal miscigenação configuraria uma espécie de "democracia racial". Por outro lado, autores como Darcy Ribeiro, ainda que afirmem a formação, no Brasil, de um “Estado uniétnico” (2006, p. 20), asseguram a falsidade de tal "democracia racial", diante dos "profundos abismos que aqui separam os estratos sociais" (2006, p. 21).

4 O conceito de cosmografia, em geral, é utilizado no sentido de ser a parte da astronomia que se preocupa com o estudo e descrição do universo. No entanto, no sentido utilizado pelo autor em comento, verifica-se que foi empregado no sentido de "cosmovisão", ou maneira de significar o mundo (dos diversos grupos sociais) relacionando este aspecto com a localização territorial (geográfica). Afirma ainda Little (2002, p.4), que a "cosmografia de um grupo inclui seu regime de propriedade, os vínculos afetivos que mantém com seu território específico, a história da sua ocupação guardada na memória coletiva, o uso social que dá ao território e as formas de defesa dele".
} 
território." Por conseguinte, aduz-se que cada território social origina-se a partir das condutas de territorialidade do grupo que o ocupa, como produto de um processo histórico de construção do espaço.

No caso do Brasil, como já mencionado, as frentes de expansão colonizadora $^{5}$ produziram diversos choques territoriais e resultaram em sucessivas alterações e dinâmicas de territorizaliação de indígenas, escravos, quilombolas, ribeirinhos e etc. Ou seja, cada localidade hoje ocupada "tradicionalmente" contou com um processo particular de construção, sendo que para entendê-los deve-se contextualizá-los historicamente. Disso decorre que nem sempre aqueles que ocupam o território possuem uma indetidade étnica com a localidade, até porque a turbulência na formação das regiões brasileiras promoveu intensa movimentação dos grupos "originários", bem como miscigenação entre estes e indíviduos de outras etnias, como explica Little (2002, p. 10):

\begin{abstract}
A noção de pertencimento a um lugar agrupa tanto os povos indígenas de uma área imemorial quanto os grupos que surgiram historicamente numa área através de processos de etnogênese e, portanto, contam que esse lugar representa seu verdadeiro e único homeland. "Ser de um lugar" não requer uma relação necessária com etnicidade ou com raça, que tendem a ser avaliadas em termos de pureza, mas sim uma relação com um espaço físico determinado. Todavia, a categoria de identidade pode se ampliar, à medida que a identidade de um grupo passa, entre outras coisas, pela relação com os territórios construídos com base nas suas respectivas cosmografias. (grifou-se)
\end{abstract}

Pode-se dizer que essa relação com o espaço físico se dá a partir do modo como se ocupa o território e, consequentemente, como são determinadas as relações sociais a partir de ações interativas ao longo do tempo de um determinado grupo que manifestam interesses comuns. Desse modo, como explica Santilli (2005, p. 140):

\begin{abstract}
O conceito de território, portanto, deve ser compreendido à luz da interpretação antropológica como o espaço necessário à reprodução física e cultural de cada povo tradicional, considerando as formas diferenciadas de uso e apropriação do espaço territorial. Tal conceito não guarda relação com o tempo imemorial, e sim com os usos, costumes e tradições dos povos tradicionais, e traduz uma ocupação coletiva do espaço, onde predomina o uso e a gestão compartilhada dos recursos naturais. (grifou-se)
\end{abstract}

\footnotetext{
5 Nem sempre os motivos da colonização tinham fundamentação econômica (ainda que os fins sempre fossem dessa natureza), mas muitas vezes fundados no próprio preconceito étnico ou de "raça". Com efeito, acerca do movimento de colonização do século XIX, mormente de alemães e italianos, afirma Celso Furtado: "As colônias criadas em distintas partes do Brasil pelo governo imperial careciam totalmente de fundamento econômico; tinham como razão de ser a crença na superioridade inata do trabalhador europeu, particularmente daqueles cuja

'raça' era distinta da dos europeus que haviam colonizado o país. Era essa uma colonização amplamente subsidiada." (FURTADO, 2007, p. 183).
} 
Neste contexto, pode-se considerar que existem territórios "dentro" do território nacional (Estado brasileiro). Ocasionalmente, grupos que se autoproclamam nações ou nacionalidades diferenciadas, dentro de uma mesma ordem de Estado-nação, geram tensões políticas, que não raras vezes culminam em conflitos separatistas ou de independência, por exemplo. De forma análoga, a existência dos territórios sociais ou tradicionais, como os em análise, certamente representa uma inconveniência para a ideologia territorial do Estado (visto que atinge o âmbito da soberania), bem como aos particulares que, na pretensão de posse de seus domínios, provocam o Estado-juiz para que lhes garanta seus títulos de propriedade que muitas vezes compreendem áreas ancestralmente ocupadas por outros grupos sociais. Essas são razões que justificam a dificuldade do Estado brasileiro em reconhecer os territórios sociais dos povos tradicionais como um grande segmento de conflitos na questão fundiária e ambiental.

Neste sentido, evidencia-se a importância de descrever, compreender, investigar e identificar as mais variadas territorialidades existentes, para que se possa reconhecê-las dentro das possibilidades legais, demarcando-as ou defendendo-as judicialmente. Esse reconhecimento é imprescindível para a preservação e conservação da biodiversidade que compreende esses territórios, bem como para a manutenção e salvaguarda dos modos de vida e da própria sobrevivência dos grupos que as ocupam.

\subsection{Conceito de povos tradicionais}

O antropólogo Paul E. Little ${ }^{6}$ (2002, p.23), a partir da análise da "razão histórica", indica três elementos que caracterizaram um grupo social como "povo ou comunidade tradicional": o (1) regime de propriedade comum; o (2) sentido de pertencimento a um lugar específico; e a (3) profundidade histórica da ocupação guardada na memória coletiva. Apesar de esses aspectos serem partilhados em todos os povos tradicionais, chama atenção o autor (2002, p.23) para o fato de que essa condição não significa semelhança entre as variadas dimensões da realidade sociocultural (práticas, crenças, identidades, línguas, etc), de modo que cada grupo mantém suas próprias idiossincrasias neste sentido.

\footnotetext{
6 Little opta pelo termo “povos" - em contraposição a "comunidades”, “grupos”, "sociedades”, etc - por acreditar que tal palavra remeta à temática tradicional do "direito dos povos", incluindo-a no debate internacional que pode auxiliar na persecução da Justiça Social por estes grupos. Esta busca consiste, de modo geral, no "reconhecimento da legitimidade de seus regimes de propriedade comume das leis consuetuedinárias que os fundamentam" (LIT TLE, 2002, p. 23).
} 
O conceito de "sociedade", em antropologia, para Viveiros de Castro (2013, p. 298), corrobora a noção de que há uma demarcação clara da singuralização dos povos tradicionais:

\footnotetext{
(uma) sociedade é uma designação aplicável a um grupo humano com algumas das seguintes propriedades: territorialidade; recrutamento principalmente por

reprodução sexual de seus membros; organização institucional relativamente autossuficiente e capaz de persistir para além do período de vida de um indivíduo; dis tintividade cultural. (grifei)
}

Como já referido, o espaço brasileiro, devido a sua biodiversidade abundante, revela uma grande diversidade cultural, fruto das múltiplas formas manifestadas de manejo dos recursos naturais, cada qual resultante das peculiares interações com o meio. Considerando as regionalidades do Brasil, é possível dizer, também com base nos critérios antropológicos supracitados, que são povos tradicionais, dentre outros: os indígenas, os quilombolas, os extrativistas em geral (seringueiros, castanheiros, quebradores de coco-babaçu, etc.), os cablocos-ribeirinhos, pescadores artesanais, caiçaras (pescadores do mar), e algumas formas de agricultura familiar ou de subsistência. Ademais, na legislação brasileira pode ser extraído, atualmente, um conceito "jurídico" de povos ou comunidades tradicionais, a partir do Decreto 6040/07, como será exposto posteriormente, que deu existência formal a essas comunidades.

\subsection{Usos diferenciados da terra e questão da propriedade}

Evidencia-se, de plano, que a relação com a terra e o ambiente nessas comunidades não é exatamente a mesma que constitui o conceito liberal-burguês de "propriedade", e que permeia as relações sociais na sociedade ocidental desde o advento do Estado Moderno. Explica Leff (2006a, p. 108) que o significado de biodiversidade ou de território é diferente entre o capitalismo e uma cultura tradicional que habita a natureza. O "uso racional dos recursos naturais" - o grau de contaminação, de equidade social, de pobreza e de qualidade de vida aceitável - é definido social e culturalmente. Sob qualquer racionalidade considerada, visões diferentes (e até opostas) se manifestam, desde o conservadorismo econômico até o ecologis mo radical, "hasta una diversidad de formas culturales de ser con la naturaleza."(LEFF, 2006a, p.108) 
Sabe-se que em muitos grupos indígenas, por exemplo, a inovação é considerada como um fenômeno social e coletivo, cujos resultados estão livre e gratuitamente disponíveis para $\operatorname{todos}^{7}$. Esse legado (saber coletivo), como explica Vandana Shiva (2005, p. 55) "não constitui propriedade alguma, mas que se entende como um conjunto de relações (mais que como um pacote de direitos económicos) representativas de uma série de responsabilidades comunitárias e individuais".

É relevante citar também a forma de produção de (estimativamente) dois terços da humanidade, a economia de subsistência ou de "sustento", que compreende a produção artesanal, a agricultura familiar, a pesca tradicional e artesanal e as economias florestais autóctones, que "produzem em equilibrio com a natureza e reproduzem a sociedade através da colaboração, da mutualidade e da reciprocidade" (SHIVA, 2005, p. 25).

Em vista disso, fica claro que há uma discrepância entre a sociabilidade ocidental representada pelo modo de produção capitalista e o direito estatal - e as variadas sociabilidades apresentadas na relação direta com a natureza. Em relação a essa última, podese dizer que são observadas nas diversas formas de expressão dos povos que têm seus entornos naturais (biomas) como hábitat, sendo que, ao longo de seu cotidiano, "formulam para diferentes situações diferentes respostas", no âmbito da organização social, produção e meios de sustento, bem como nas significações culturais (crenças, música, mitos) e, "consequentemente, na criação de normas de relacionamento (o Direito)" (ARAUJO, 2013, p. 275).

\footnotetext{
${ }^{7}$ Já chamava a atenção Gilberto Freyre, em Casa Grande \& Senzala (apesar de toda a controvérsia em torno de tal obra) que no Brasil a "noção de propriedade" fosse até então um campo de "conflito entre antagonismos os mais violentos", devido, entre outros, à antiga oposição entre o "comunismo do ameríndio e a noção de propriedade privada do europeu", que se manifestava nas divergências entre o "descendente do índio comunista, quase sem noção de propriedade posse individual, e o descendente do português particularista que até princípios do século XIX viveu, entre alarmes de corsários e ladrões, a enterrar dinheiro em botija [...]" (FREYRE, 2013).
} 
Ademais, as pesquisas acadêmicas de diversas áreas têm desmentido, contemporaneamente, a visão obsoleta de que o território brasileiro, antes da invasão europeia, era um conjunto de mata "intocada" ${ }^{8}$, povoado por grupos esparsos de autóctones de cultura mais ou menos homogênea. Com efeito, além de uma estrutura territorial complexa - multiétnica e multilinguística - revelada pela arqueologia e antropologia, sabe-se que "as populações indígenas estavam articuladas ao ambiente amazônico de maneira muito diferente do complexo agroindustrial do capitalismo tardio" (VIVEIROS DE CASTRO, p. 103, 2008), visto que a ocupação tradicional, em geral, dá-se (em escala milenar) sem impactos ambientais (negativos) evidentes. Pelo contrário, a natureza "antropizada" (biodiversidade enriquecida e estimulada pela ação antrópica) não é resultado de qualquer usufruto humano. Em outras palavras, como ironiza Viveiros de Castro (p. 103, 2008), "para a floresta amazônica, muito Kuikuru não é a mesma coisa que muito gaúcho". Dessa forma, refere Araujo (2013, p. 279):

[...] se pensa em termos de sociobiodiversidade, is to é, a relação entre o ser humano e natureza, na qual as práticas sociais de produção ou de vivência comunitária revelam modelos próprios e específicos no trato com a biodiversidade, ou seja, comunidades cuja cultura é fruto da convivência harmônica e sustentável com o seu entorno ambiental. (grifo)

É imprescindível, para que se pense em "direitos" da sociobiodiversidade, a adoção de uma perspectiva de pluralismo jurídico, no sentido de que se reconhece que existem variadas formas de regulação social, muitas delas de raízes milenares, aplicadas consuetudinariamente, na medida em que independem de qualquer positivação no sentido formal trazido pelo Estado Moderno.

\footnotetext{
${ }^{8}$ Sobre is so, ver: DIEGUES, Antonio Carlos Santana. O mito moderno da natureza intocada. 3 ed. São Paulo: Hucitec, 2001.
} 
Os registros etnográficos confirmam (LITTLE, 2002) a existência, no território brasileiro, dessas distintas formas de propriedade social. Locais em que a razão histórica (forma específica de sociabilidade) contrapõe-se à razão instrumental hegemônica (do Estado), funcionando em um regime coletivo que não se encaixa na dicotomia público/privado. Com efeito, por estarem sob usufruto de um grupo determinado de indivíduos, as terras tradicionais poderiam ser classificadas como "privadas". Mas a experiência indica, com clareza, que as regras costumeiras atribuem o uso coletivo a essas terras, sendo que não teriam como existir dentro da lógica do mercado. Até mesmo pela própria dinâmica sustentável de manejo dos recursos e a preocupação em conservar o bem para o uso de todos, essas "redes de direitos e de controlo escapam às partilhas privatistas, para se moldarem aos contornos dos paradigmas ecológicos ou, em matéria cultural, à integridade dos locais e dos estilos" (OST, 1997, p. 371).

Afirma Santos, nesse sentido, não ser por acaso que no início do terceiro milê nio grande parte da biodiversidade do planeta esteja na posse de povos indígenas e de comunidades camponesas, pois para eles, "a natureza nunca foi um recurso natural, foi sempre parte da sua própria natureza e assim preservaram, preservando-se também eles, sempre que conseguiram escapar à destruição que o encontro colonial com o ocidente produziu." (SANTOS, 2010, p. 189). Assim, como explica Araujo (2013, p. 288):

[...] tem-se o direito de propriedade, cuja norma geral, seja constitucional ou infracosntitucional, tendeu sempre ao aspecto excludente da individualidade. Já em sentido contrário, as normas legadas pelos antepassados e as diversas comunidades disseminadas na sociedade realçaram sempre os interesses de todos os comunitários, is to é, gerando um direito comum, não excludente.

Apesar da longa duração das ocupações tradicionais (no caso dos indígenas, fala-se em posse imemorial), elas sempre ficaram fora da consideração do regime de propriedade imposto pela razão instrumental do Estado. Com efeito, desde o processo de colonização, passando o Brasil pela forma política de Colônia, Império e República, até o presente

\footnotetext{
${ }^{9}$ Não se ignora a formação, desde o século XIX e XX, de comunidades e grupos, com identidade própria, que ocuparam espaços territoriais de forma coletiva, criando normas de convivência social e econômica que estabelecem o "privado" (residências e seus entornos, bens pessoais, etc) sem prejuízo do "coletivo" (rios, florestas, campos, etc), vicejando assim o sentido de "comunidade".
} 
momento, houve desconsideração dos povos tradicionais e sua regulação autônoma. A persistência desses grupos, em outros termos, a sua própria existência até hoje, deve-se à própria expressão de sua territorialidade, que se situa na memória coletiva de seus membros e manifesta uma força de coesão cultural que mantém incorporadas as dimensões simbólicas e identitárias na relação do grupo com sua área de vivência ao longo do tempo.

Portanto, as reivindicações territoriais dos povos tradicionais possuem uma relevância que se assenta na razão histórica de construção do território, de modo que os conflitos que emergem entre a ocupação tradicional e os interesses econômicos devem ser vistos a partir de uma perspectiva de justiça, que independe de qualquer positivação normativa, mas, antes, desperta como a espontânea inquietude diante dos genocídios que acompanham a degradação ambiental ao longo do tempo. Tal contexto permite ao jurista François Ost (1997, p.393) caracterizar o que chama de "meio injusto", como segue:

[...] de um lado, uma cultura tradicional, respeitadora do ambiente e fonte de subsitência para as populações locais, do outro, a intrusão de poderosos interesses econômicos, traduzindo-se pela destruição de centenas de milhares de hectares de florestas. [...] o meio injusto não é fruto do acaso ou da fatalidade; ele resulta, pelo contrário, de desequilíbrios econômicos e sociais perfeitamente identificáveis.

Em tal meio, atinge-se o ápice das verticalidades "assujeitadoras" dos povos tradicionais no contexto contemporâneo da globalização, conjuntura que merece atenção.

\subsection{Globalização econômica e sociobiodiversidade}

Como já referido, o entrechoque cultural do processo colonizatório, além de acarretar o genocídio de parcela dos povos originários, produziu um reordenamento territorial e a geração de novas etnias e grupos ocupantes de diferentes espaços regionais. Ainda que a primeira fase da globalização - a fase dos "descobrimentos" (iniciada no século XV), do Brasil Colônia - tenha sido a mais radical e dizimadora de grupos étnicos, as sucessivas ondas desse processo seguiram produzindo verticalidades opressoras. Como explica Darcy Ribeiro (2006, p. 27), o conflito entre o povo dominador e os dominados se deu em todos os níveis, seja no "biótico" (guerra bacteriológica), no "ecológico" (pela disputa do território para outros fins) e no "econômico e social" (pela escravização e mercatilização das relações de trabalho).

Às versões mais recentes do capitalismo e imperialismo globais, o sociólogo Boaventura de Sousa Santos atribui a classificação de "globalização de cima para baixo", propondo a definição de globalização como "o processo pelo qual determinada condição ou 
entidade local estende a sua influência a todo o globo e, ao fazê-lo, desenvolve a capacidade de designar como local outra condição social ou entidade rival” (SANTOS, 2010, p. 438).

Neste sentido, um dos processos desencadeados pela globalização hegemônica, o "globalismo localizado", corresponde ao impacto dos imperativos transnacionais às práticas locais, inserindo-se nesse contexto a realidade dos povos tracionais, que têm suas especificidades "desintegradas, marginalizadas, excluídas, desestruturadas e, eventualmente, reestruturadas sob a forma de inclusão subalterna" (SANTOS, 2010, p. 438).

É interessante referir, a respeito disso, um neologismo proposto pelo geógrafo brasileiro Milton Santos, que, ao constatar o caráter totalitário da globalização, cunhou o termo "globalitarismo". Sobre tal conjuntura, aduz o autor (2007, p. 23):

[...] há um uso privilegiado do território pelas forças hegemônicas. Estas, por meio de suas ordens, comandam verticalmente o território e a vida social, relegando o Estado a uma posição de coadjuvante ou de testemunha, sempre que ele se retira, como no caso brasileiro, do processo de ordenação do uso do território.

Entretanto, "o que acontece com o território brasileiro é uma das evidências da impossibilidade de continuação do processo globalitário" (SANTOS, 2007, p. 25), pois a própria abundância de sociobiodiversidade aqui encontrada apresenta resistência às verticalidades impostas pela racionalidade dominante ${ }^{10}$. Evidentemente, é inegável que as fronteiras territoria is - assim como todas, e principalmente a do capital (fluidez) - têm se mostrado mais tênues com o processo de globalização. Mas isso não impede a identificação dessas fronteiras, nem mesmo de "regiões":

\begin{abstract}
A região fora, no passado, sinônimo de territorialidade absoluta de um grupo através de suas características de identidade, de exclusividade e de limites. Hoje, o número de mediações é muito grande, o que induz, frequentemente, à confusão de imaginar que a região não mais existe. [...] não pensamos que a região haja desaparecido. O que esmaeceu foi a nossa capacidade de reinterpretar e de reconhecer o espaço em suas divisões e recortes atuais. (SANTOS, 1994, p.48-50)
\end{abstract}

\footnotetext{
${ }^{10}$ Explica o autor que "essa racionalidade [dominante] supõe contra-racionalidades. Essas contra-racionalidades se localizam, de um ponto de vista geográfico, nas áreas menos 'modernas' e, do ponto de vista social, nas minorias. As minorias se definem pela sua incapacidade de subordinação completa às racionalidades hegemônicas . As minorias étnicas, sexuais (de gênero) e outras têm mais dificuldades para aceitar e atender às exigências da racionalidade". (SANTOS, 1994, p. 53)
} 
Portanto, fica demonstrada a importância, sobretudo acadêmica, de aplicar um olhar crítico na disposição espacial da sociedade, para que seja possível a identificação dos pontos de tensão (atritos e conflitos simbólicos), que indicam os motivos culturais, muitas vezes ocultos ou "naturalizados" ao olhar comum, da segregação territorial entre diferentes grupos.

Exatamente por isso que a racionalidade hegemônica, que lida com a natureza como "externalidade", também é inapta em mensurar, até mesmo epistemologicamente, a condição dos povos tradicionais. Necessita-se introduzir aos "ecologistas de mercado" uma dimensão que lhes escapa totalmente: "a regulação simbólica das comunidades de utilizadores partilhando uma cultura, tradições e valores, que induzem, precisamente, a complementaridade dos usos pela moderação das subtracções" (OST, 1997, p.162). Feito esse aporte teórico, torna-se oportuna a análise do conjuto jurídico-normativo em torno da temática proposta.

\section{CONJUNTO NORMATIVO RELATIVO AOS POVOS TRADICIONAIS}

A Constituição Federal de 1988, além do art. 225 (Do Meio Ambiente), in totum, trouxe ao normativo brasileiro à preocupação com a proteção da biodiversidade, ao patrimônio genético e às diversas culturas presentes em nosso vasto território, especialmente nos artigos 215 (destaca-se o $\S 1^{\circ}$, “O Estado protegerá as manifestações das culturas populares, indígenas e afro-brasileiras, e das de outros grupos participantes do processo civilizatório nacional") e 216, referente ao "patrimônio cultural" (BRASIL, 1988). Tais artigos referemse a "grupos participantes do processo civilizatório nacional" e "grupos formadores da sociedade brasileira", não restringindo, portanto, interpretações que ampliem o rol de sociedades que adequem-se à previsão do texto legal. Com efeito, além das expressamente referidas - indíge nas e afro-brasileiras - que são as identidades mais marcantemente manifestadas no âmbito nacional como tradicionais ou ancestrais, é possível identificar diversos outros grupos que, na turbulenta dinâmica de colonização (miscingenação e reorganização espacial), inserem-se como participantes/formadores do território nacional.

Destarte, a Carta Política de 1988, além de responsabilizar o Estado pela proteção das culturas populares, indígenas e afro-brasileiras (art. 215), atribui status de Patrimônio aos bens de natureza imaterial e material (aqui se encaixam os territórios). Ainda, no $\S 1^{\circ}$ do artigo 216, lê-se que o "Poder Público, [...] promoverá e protegerá o patrimônio cultural 
brasileiro, por meio de [...] desapropriação, e de outras formas de acautelamento e preservação", demonstrando o papel proativo legado ao Estado na persecução e garantia dos bens constitucionalmente protegidos. Neste sentido, pode-se dizer que a inciativa "patrimonializadora" do artigo 216 da CF/88 afina-se com aquela referida por Ost (1997, p. 381):

\begin{abstract}
Patrimonializar um espaço, um recurso, um bem, é reconhecer que nele são inscritos não apenas interess es de consumo, mas igualmente valores identitários (valores que dão sentido à existência, asseguram a sua identidade e o seu desenvolvimento), uma parte de trabalho e de originalidade, um traço de tradição, uma forma de beleza ou de estranheza, uma via do porvir; numa palavra como em cem: condições de possibilidade do humano.
\end{abstract}

Por esta mesma via, foi dedicado na Lei Maior um capítulo exclusivo aos povos originários (CAPÍTULO VIII - DOS ÍNDIOS), sendo que neste excerto, reconhece-se o "direito originário" sobre as terras por eles tradicionalmente ocupadas, por força do artigo 231 da CF/88. Destacam-se, sobremaneira, os seguintes aspectos de tal dispositivo: (1) a responsabilidade estatal (da União) em demarcar e proteger os "direitos originários" dos povos indígenas, a (2) definição legal de "terras tradicionalmente ocupadas", a (3) atribuição de posse permanente de tais territórios pelos índios, a (4) indisponibilidade/inalienabilidade e imprescritibilidade de tais direitos, bem como a (5) nulidade de pleno direito dos atos que os usurpem (BRASIL, 1988).

Segundo dados do Instituto Socioambiental ${ }^{11}$ (ISA, 2014), existem mais de 240 povos indígenas no Brasil que somam, segundo o Censo IBGE 2010, 896.917 pessoas. Destes, 324.834 vivem em cidades e 572.083 em áreas rurais, o que corresponde aproximadamente a $0,47 \%$ da população total do país. Entre estes povos existe uma infinidade de variação cultural, linguística, religiosa e de organização social. Ainda assim, como já referido no primeiro capítulo, é unânime entre as comunidades indígenas a propriedade coletiva da terra, embora o produto do trabalho, eventualmente, seja individual ou familiar. De qualquer forma, sabe-se que, com o uso compartilhado dos recursos, são inexistentes os casos de escassez socialmente provocada nas comunidades indígenas. Ademais, como insta ressaltar:

\footnotetext{
${ }^{11}$ Disponível em http://pib.socioambiental.org/pt/c/0/1/2/populacao-indigen a-n o-brasil (Acesso em 20jul2015).
} 


\begin{abstract}
A história desses povos não começou em 1492 (em muitos casos, bem ao contrário, ela terminou ali), assim como não foi somente a partir daquela data que os índios passaram de uma daptação à natureza a uma adaptação $d a$ natureza - mesmo que os efeitos da intervenção humana sobre o ambiente amazônico tenham mudado dramaticamente de escala, e sobretudo de direção (em lugar de estimulando, destruindo a biodiversidade). (VIVEIROS DE CASTRO, 2013, p. 341).
\end{abstract}

Outro grupo que, assim como os indígenas, historicamente se sobresai na resistência étnico-cultural na ocupação territorial brasileira são as comunidades de Quilombos. Mesmo não obtendo espaço privilegiado no texto "principal" da Constituição Federal de 1988, aos remanescentes deste grupo foi reservado o artigo 68 do Ato das Disposições Constitucionais Provisórias - ADCT (que, por evidente, ostenta status de norma constitucional), com o seguinte mandamento: "Aos remanescentes das comunidades dos quilombos que estejam ocupando suas terras é reconhecida a propriedade definitiva, devendo o Estado emitir-lhes os títulos respectivos". Sobre os compromissos constitucionais acima expostos, melhor explicam Canotilho e Morato Leite (2011, p. 312):

O reconhecimento pela ordem jurídica da obrigação de proteção de uma relação espiritual-cultural coma terra, com a qual são mantidos vínculos de interdependência histórica, econômica e ecológica - que são permanentes, indissociáveis e intransferíveis -, impede a legitimação de qualquer prática que venha restringir, em alguma medida, o exercício pleno e integral de manifestações, o que constitui, agora, verdadeira prática constitucional, integrante do próprio núcleo de identidade de um Estado de Direito e de uma democracia constitucional multiculturais.

Considerando que as convenções internacionais, em matéria de Direitos Humanos, têm status $^{12}$ de Emenda Constitucional, torna-se imperioso mencionar a Convenção sobre Diversidade Biológica (CDB), ocorrida em 1992 durante a "Rio-92", ratificada pelo Brasil e internalizada pelo Decreto 2519/98, que estabelece normas e princípios que devem reger o uso e a proteção da biodiversidade dos países signatários. Especialmente significativa a alínea c, do art. 10 da referida Convenção, em que se lê: "(c) Proteger e encorajar a utilização costumeira de recursos biológicos de acordo com práticas culturais tradicionais compatíveis com as exigências de conservação ou utilização sustentável;". Ainda mais pertinente para o tema aqui tratado é a Convenção $\mathrm{n}^{\circ} 169$ da OIT, que, até mesmo por incluir o critério da “territorialidade específica”, merece atenção especial.

\title{
2.1 A Convenção 169 da OIT (Decreto no 5051/04)
}


No âmbito internacional, também deve ser citada a convenção n ${ }^{\circ} 169$ da Organização Internacional do Trabalho (OIT), "sobre Povos indígenas e tribais", adotada em Genebra, em 1989, que foi internalizada pelo Decreto $\mathrm{n}^{\circ} 5051$ de 2004 pelo Brasil. Ao destacar a contribuição dos povos indígenas e tribais à diversidade cultural, à harmonia social e ecológica da humanidade a Convenção trata, em diversos dispositivos, o tema aqui abordado, dentre os quais questões de autonomia política e cidadania dos indivíduos pertencentes a esses grupos. Destaca-se o capítulo II, de tal normativo, que trata das Terras, determinando o artigo 13 que "os governos deverão respeitar a importância especial que para as culturas e valores espirituais dos povos interessados possui a sua relação com as terras ou territórios" bem como "os aspectos coletivos dessa relação". O mesmo dispositivo esclarece que o termo "Terras" deverá "incluir o conceito de territórios, o que abrange a totalidade do habitat das regiões que os povos interessados ocupam ou utilizam de alguma outra forma", demosntrando estar de acordo com as concepções antropológicas já expostas aqui. Ainda, dispõe o artigo 14 que:

Dever-se-á reconhecer aos povos interessados os direitos de propriedade e de posse sobre as terras que tradicionalmente ocupam. Além disso, nos casos apropriados, deverão ser adotadas medidas para salvaguardar o direito dos povos interessados de utilizar terras que não estejam exclusivamente ocupadas por eles, mas às quais, tradicionalmente, tenham tido acesso para suas atividades tradicionais e de subsistência.

A referida convenção demonstrou grande avanço, mesmo que seus postulados, pela própria estrutura estabalecida, sejam algumas vezes de difícil aplicação. Ainda assim, essa norma tem servido de fundamento nas cortes superiores brasileiras.

\footnotetext{
${ }^{12}$ Art. $5^{\circ}, \S 3^{\circ} \mathrm{CF} / 88$ : “Os tratados e convenções internacionais sobre direitos humanos que forem aprovados, em cada Casa do Congresso Nacional, em dois turnos, por três quintos dos votos dos respectivos membros, serão equivalentes às emendas constitucionais".
} 


\subsection{O Decreto $\mathrm{n}^{0}$ 6040/07 e a Lei $\mathrm{n}^{0} \mathbf{1 3 . 1 2 3 / 1 5}$}

Conceitualizar os "povos tradicionais" em uma categoria, ressalvado o risco de tratálos como conjunto humano hermético e estagnado no tempo, pode ser uma ferramenta capaz de resguardar "a existência de regimes de propriedade comum, o sentido de pertencimento a um lugar, a procura de autonomia cultural e práticas sustentáveis” que esses variados grupos demonstram (LITTLE, 2002, p. 23). Neste sentido, em âmbito infraconstitucional, teve-se, recentemente, a edição do Decreto $\mathrm{n}^{\mathrm{o}} 6.040$ de 2007, que instituiu a Política Nacional de Desenvolvimento Sustentável dos Povos e Comunidades Tradicionais, inclusive fornecendo um conceito legal de "Povos e Comunidades tradicionais", em seu art. $3^{\circ}$, inciso I, identificando-os como:

grupos culturalmente diferenciados e que se reconhecem como tais, que possuem formas próprias de organização social, que ocupam e usam territórios e recursos naturais como condição para sua reprodução cultural, social, religiosa, ancestral e econômica, utilizando conhecimentos, inovações e práticas gerados e transmitidos pela tradição;

O decreto também estabeleceu um conceito para "territórios tradicionais", definindoos, também no artigo $3^{\circ}$, inciso II, como:

\footnotetext{
os espaços necessários a reprodução cultural, social e econômica dos povos e comunidades tradicionais, sejam eles utilizados de forma permanente ou temporária, observado, no que diz respeito aos povos indígenas e quilombolas, respectivamente, o que dispõem os arts. 231 da Constituição e 68 do Ato das Disposições Constitucionais Transitórias e demais regulamentações;
}

Esta norma representa grande avanço na temática, visto que, antes de sua edição, não havia consenso quanto à definição de povo ou comunidade tradicional. Com efeito, quando da tramitação do Projeto da Lei do "SNUC" (Sistema Nacional de Unidades de Conservação), houve intenso debate entre as correntes "preservacionista" e "socioambientalista", do movimento ambientalista, sobremaneira em torno da definição da categoria "população tradicional". Em função do desacordo insolucionável, o trecho do texto acabou por ser vetado pela Presidência da República. Com efeito, foi acertada a decisão do veto, visto que no trecho em debate, a respeito da caracterização de população tradiconal, exigiam-se condicionamentos estranhos às comunidades, referentes ao tempo necessário de ocupação e delimitação do território, para sua classificação como tradicional.

Realmente, mais apropriado o texto do atual Decreto no6040, que assegura o direito à diversidade, delegando aos povos o critério da autodenominação ou autorreconhecimento. Demonstra-se que houve abertura, em termos de epistemologia jurídica, à influência de 
fundamentos atropológicos, para reconhecer, a partir de uma hermenêutica multicultural e transvalorativa, a importância do protagonismo do "outro" na definição, como sujeito, de seu lugar/território como "espaço jurídico diferenciado" (SANTILLI, 2005).

Recentemente, foi sancionada a Lei $\mathrm{n}^{\circ}$ 13.123, em maio de 2015, considerada o "Marco Legal da Biodiversidade", que visa regular a fomra de acesso aos elementos do patrimônio genético nacional, bem como aos conhecimentos tradicionais associados. Apesar de estar suscitando controvérsias quanto às formas de repartição de benefícios previstas, tal norma reafirmou o conteúdo do decreto já abordado, considerando como "comunidade tradicional", em seu art. $2^{\circ}$, inciso IV, qualquer grupo culturalmente diferenciado que além de se reconhecer como tal, "possui forma própria de organização social e ocupa e usa territórios e recursos naturais como condição para a sua reprodução cultural, social, religiosa, ancestral e econômica, utilizando conhecimentos, inovações e práticas geradas e transmitidas pela tradição”.

Desataca-se, ainda, que foi lançado em 2009 o "Plano Nacional de Promoção das Cadeias de Produtos da Sociobiodiversidade", em que são previstas ações de apoio às comunidades que produzem de forma tradicional, com o fortalecimento dessas estruturas sociais e produtivas, bem como a promoção e o apoio à produção e ao extrativismo sustentável, dentre outras medidas.

\subsection{Direitos étnicos e culturais: marco do direito da sociobiodiversidade}

Fica evidenciado, pelo exposto, que é possível encontrar uma conceitualização de povos tradicionais, a partir de contribuições e aportes antropológicos. Da mesma forma, vê-se que a diversidade cultural (juntamente com a biodiversidade), na sua expressão pelos povos tradicionais por meio de suas plurais territorialidades auferiram, em âmbito constitucional e infraconstitucional, albergue jurídico e dever de proteção do Estado. Com isso, contemporaneamente nota-se o surgimento de novas construções doutrinárias acerca do tema, como refere Camerini (p. 158, 2012):

[...] anota-se o aparecimento, na primeira década do século XXI, de um novo campo da prática e da ciência jurídica, o direito étnico, com a proposta de enfrentar temas relacionados àgarantia de direitos fundamentais das chamadas comunidades e povos tradicionais, minorias sociais, povos indígenas e tribais, etc., e desenvolver métodos próprios de interpretação das normas jurídicas correlatas, existentes em âmbito nacional e internacional. Nessas pesquisas assume especial relevância o problema do reconhecimento das terras tradicionalmente ocupadas [...]. 
Tais construções (incluindo a categoria mencionada do "direito étnico") são imprescindíveis para reforçar a arcabouço jurídico-interpretativo e fornecer sustento aos argumentos - na prática jurídica latu sensu - em defesa dos grupos minoritários em questão. Especificamente, no âmbito interpretativo dos tribunais, é necessária a oxigenação dos princípios hermenêuticos para que se comuniquem discursivamente e constitucionalmente com os pressupostos aqui versados.

Nesse sentido, releva-se o debate acadêmico em torno da interpretação jurídica que envolve a temática em questão, promovendo-se, como proposto por Santilli (2005, p. 34) um paradigma decorrente de "diálogo intercultural amplo e que se baseia no pressuposto de que todas as culturas têm um valor de dignidade humana, o que permite uma hermenêutica multicultural $^{13}$ e transvalorativa". Nesta esteira, também são absolutamente adequados os conceitos de Boaventura de Sousa Santos (2010, p.442) de "multiculturalismo emancipatório" e "hermenêutica diatópica" (2010, p. 447), ambos a respeito de uma visão do "outro" em sua alteridade, a fim de suscitar a abertura epistemológica do direito que se harmonize com os princípios de autonomia cultural, pluralismo jurídico e interculturalidade. Da mesma forma, em antropologia procura-se por um ponto de vista "multiversal", isto é: ponto de vista capaz de gerar e desenvolver a diferença (VIVEIROS DE CASTRO, 2013, p. 316). Eis o desafio e a proposta de um marco jurídico em torno dos direitos que envolvem a sociobiodiversidade.

\section{CONSIDERAÇÕES CONCLUSIVAS}

Verifica-se que o tema abordado é eminentemente transdisciplinar, sendo que permite um enfoque por diversas matizes teóricas que, adequadamente discutidas, podem trazer contribuições indispensáveis à pesquisa e até mesmo à prática jurídica. Com efeito, o caminho percorrido permitiu a observação de alguns conceitos antropológicos (território, cultura, povos), que facilitam a compreensão das cosmovisões alternativas de cada grupo societário, e as consequências na definição e estabelecimento de cada territorialidade específica.

\footnotetext{
${ }^{13}$ Sabe-se que existe certa discrepância entre os conceitos de "multiculturalismo" e "interculturalismo", que vem gerando debates acadêmicos. Tal diferenciação não é foco do presente trabalho, mas registra-se a preferência pelo termo "intercultural" (mais afeito ao caráter emancipatório), em desfavor do "multicultural" (de caráter mais integrativo, muitas vezes pela via do próprio mercado).
} 
De outra banda, a partir de uma razão crítica (sociológica, política e histórica) demonstraram-se os conflitos e choques culturais na ocupação e construção do Estado brasileiro, sendo que as atuais contradições e (des)igualdades são desnudadas nesse devir histórico. A tal processo soma-se a realidade da globalização econômica, aqui brevemente trabalhada, mas que aparece como ápice da dominação da razão hegemônica, sendo que sem dúvida alguma facilita - em um "assujeitamento" vertical - a descaracterização cultural e o desatrelamento territorial dos povos tradicionais pelo ritmo/fluxo do capital.

Ademais, verificou-se também que existe um aparato normativo que dá ensejo à proteção dos povos tradicionais e sua afirmação em seus territórios. Com efeito, os artigos citados da CF/88 e a Convenção 169 da OIT conferem um caráter de direito fundamental às reivindicações territoriais dos povos tradicionais no Brasil. Ademais, o recente decreto $n^{\circ}$ 6040/07 traz um conceito jurídico de tais povos, sendo que sua edição é um significativo avanço, até mesmo porque reforça a importância da "autodefinição" do grupo para seu enquadramento na categoria, permitindo uma autonomia cultural nesse sentido.

Em vista disso, permite-se hoje falar em direitos étnicos e culturais, bem como o conceito recente, aqui trabalhado, dos "direitos da sociobiodiversidade", que resultam da consideração de que existem regulações simbólicas (muitas vezes milenares) paralelas ao direito oficial do Estado, sendo que a coesão social das comunidades locais dá-se dessa forma consuetudinária, merecendo destaque a relação espiritual-cultural com a terra, que deve ser levada em consideração quando dos conflitos com a propriedade privada.

Nesse sentido, tais categorias jurídicas aparecem como alternativa, a partir de uma perspectiva de pluralismo jurídico e interculturalidade, para o reconhecimento do usufruto de caráter coletivo empregado por essas comunidades, reforçando a relevância de sua legitimação perante a sociedade e o Estado.

Imprescindível, diante disso, o reconhecimento de que a questão fundiária e ambiental ultrapassa a questão da redistribuição (ainda que importantíssima e ainda incipiente) para alocar-se também no problema da afirmação territorial, tornando-se cogente a promoção, seja a partir do Poder Executivo ou Legislativo, seja a partir dos tribunais - por meio de uma jurisdição democrática e responsável com as promessas constitucionais - dos direitos étnicos e culturais que assistem os povos e comunidades tradicionais. 


\section{REFERÊNCIAS}

ARAUJO, Luiz Ernani Bonesso de. O Direito da Sociobiodiversidade. In: Direitos emergentes na sociedade global: anuário do programa de pós-graduação em direito da UFSM. Orgs: TYBUSCH, Jerônimo Siqueira (...) [et al]. Ijuí: Unijuí, 2013. p. 269-291.

BRASIL. Congresso Nacional. Constituição da República Federativa do Brasil de 1988. Disponível em: http://www.planalto.gov.br/ccivil_03/constituicao/constituicaocompilado.htm (Acesso em 22jun2015).

. Presidência da República. Decreto no 2519/98. Disponível em http://www.planalto.gov.br/ccivil_03/decreto/D2519.htm (Acesso em 13jun2015).

Presidência da República. Decreto $\mathbf{n}^{\mathbf{0}}$ 4.887/03. Regulamenta o procedimento para identificação, reconhecimento, delimitação, demarcação e titulação das terras ocupadas por remanescentes das comunidades dos quilombos de que trata o art. 68 do ADCT. Disponível em http://www.planalto.gov.br/ccivil_03/decreto/2003/d4887.htm (acesso em 04jun2015).

. Presidência da República. Decreto no 5.051. Publica a Convenção 169 da OIT. Disponível em http://www.planalto.gov.br/ccivil_03/_ato2004-2006/2004/decreto/d5051.htm (Acesso em 05jun2015).

. Presidência da República. Decreto no 6.040. Disponível em http://www.planalto.gov.br/ccivil_03/_ato2007-2010/2007/decreto/d6040.htm (Acesso em 13jun2015).

Congresso Nacional. Sistema Nacional de Unidades de Conservação (SNUC). Lei no 9985 de 2000, disponível ehttp://www.planalto.gov.br/ccivil_03/leis/19985.htm (Acesso em 13jun2015).

Plano Nacional de Promoção das Cadeias de Produtos da Sociobiodiversidade. http://www.capa.org.br/uploads/publicacoes/PLANO_NACIONAL_DA_SOCIOBIODIVER SIDADE julho_2009.pdf (Acesso em 03jun2015)

CANOTILHO e LEITE, José Joaquim Gomes e José Rubens Morato - Direito

Constitucional Ambiental Brasileiro - $4^{\mathrm{a}}$ ed. rev. - São Paulo: Saraiva, 2011.

CAMERINI, João Carlos Bemerguy. Os quilombos perante o STF: A emergência de uma jurisprudência dos direitos étnicos (ADIN 3.239-9). Revista Direito GV, São Paulo, 8(1), p. 157-182, Jan-jun. 2012.

CAPRA, Fritjof. A Teia da Vida. São Paulo: Cultrix, 2001.

DIEGUES, Antonio Carlos Santana. O mito moderno da natureza intocada. 3 ed. São Paulo: Hucitec, 2001

FREYRE, Gilberto. Casa-grande \& Senzala: formação da família brasileira sob o regime patriarcal. 52 ed. São Paulo: Global, 2013. 
FURTADO, Celso. Formação econômica do Brasil. 34 ed. São Paulo: Companhia das Letras, 2007.

LEFF, Enrique. Aventuras de la epistemologia ambiental: de laarticulación de ciências al diálogo de saberes. México: Siglo XXI, 2006a.

Racionalidade Ambiental: a reapropriação social da natureza. Rio de Janeiro: Civilização Brasileira, 2006b.

LITTLE, Paul E. Territórios Sociais e Povos Tradicionais no Brasil: Por uma antropologia da territorialidade. Série Antropologia no 322. Brasilia, UnB: 2002.

MORIN, Edgar. Introdução ao pensamento complexo. 4 ed. Porto Alegre: Sulina, 2011.

OST, François. A Natureza à margem da lei: a ecologia à prova do direito. Traduzido por Joana Chaves. Lisboa: Instituto PIAGET, 1997.

RIBEIRO, Darcy. O povo brasileiro: a formação e o sentido do Brasil. 1 ed. São Paulo: Companhia das Letras, 2006.

SANTILLI, Juliana. Socioambientalismo e novos direitos: proteção jurídica à diversidade biológica cultural. São Paulo: Peiropolis, 2005.

SANTOS, Boaventura de Sousa. A gramática do tempo: para uma nova cultura política. 3 . ed. São Paulo: Cortez, 2010.

SANTOS, Milton. Técnica, espaço, tempo: globalização e meio técnico-científico informacional. Versão online, disponível em PDF em: http://reverbe.net/cidades/wpcontent/up loads/2011/livros/tecnica-espaco-tempo-milton-santos.pdf (Acesso em 30ago2014), Hucitec, São Paulo: 1994.

Território e Sociedade: entrevista com Milton Santos. Entrevistado por Odette Seabra, Mônica de Carvalho, José Corrêa Leite. $2^{\mathrm{a}}$ ed. $3^{\mathrm{a}}$ reimpressão. Editora Fundação Perseu Abramo, São Paulo: 2007.

SHIVA, Vandana. Manifesto para una democracia de laTierra: Justicia, sostenibilidad y paz. Traducción Albino Santos Mosquera. Barcelona: EdicionesPaidós Ibérica, S.A., 2005.

VIVEIROS DE CASTRO, Eduardo. A inconstância da alma selvagem(e outros ensaios de antropologia). 5 ed. São Paulo: Cosac Naify, 2013.

Socioambiental 2008. São Paulo: Instituto Socioambiental (ISA), 2008. p. 102-103.

Disponível em:

http://books.google.com.br/books? id=ggD3In5t_FIC\&printsec=frontcover\&hl=pt-

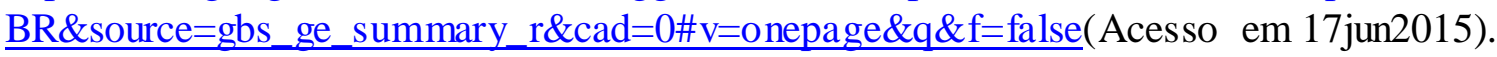

